\title{
Habilidades de consciência fonológica em crianças de escolas pública e particular durante o processo de alfabetização
}

\author{
Phonological awareness in children from public schools and \\ particularly during the process of literacy
}

\author{
Thaís dos Santos Gonçalves', Thaíla Affonso Pimenta Neves², Ana Paola Nicolielo³, Patrícia Abreu Pinheiro \\ Crenitte ${ }^{4}$, Simone Aparecida Lopes-Herrera ${ }^{4}$
}

\begin{abstract}
RESUMO
Objetivo: Verificar e comparar habilidades de consciência fonológica (CF) de crianças estudantes de escola pública e particular, em processo de alfabetização. Métodos: Foi aplicado um teste de CF em 70 crianças da primeira série do Ensino Fundamental, sendo 35 estudantes de escola pública e 35 de escola particular, no início (pré-teste) e no final (pós-teste) do ano letivo. Resultados: Todas as crianças obtiveram melhora no desempenho, quando comparados o pré e o pós-teste. No pré-teste, os melhores escores foram relativos às provas que envolviam o nível silábico e rimas. No entanto, comparando-se o pré-teste com o pós-teste, as provas de nível fonêmico foram as que resultaram em índices significativos de melhora em toda a amostra. As crianças da escola particular obtiveram maior pontuação na maioria das provas, assim como maior número total de pontos no pré-teste e no pós-teste, em relação às crianças da escola pública. Houve redução da diferença entre as escolas no desempenho da $\mathrm{CF}$ no final do ano letivo. Conclusão: Todas as crianças apresentaram melhora nas habilidades de CF com o processo de alfabetização. As crianças da escola particular demonstraram melhor desempenho, principalmente no pré-teste, indicando possível influência dos aspectos socioeconômicos no desenvolvimento dessas habilidades. As habilidades de rimas e as habilidades silábicas desenvolveram-se antes do processo de alfabetização e as habilidades de consciência fonêmica foram desenvolvidas concomitantemente com esse processo. Enfatiza-se, ainda, na amostra estudada, a importância do ensino da escola pública na diminuição da discrepância dessas habilidades entre as escolas, no final do ano letivo.
\end{abstract}

Descritores: Aprendizagem; Linguagem; Linguagem infantil; Desenvolvimento da Linguagem; Educação

\begin{abstract}
Purpose: To verify and compare phonological awareness (PA) abilities of public and private school children in the literacy process. Methods: A test of phonological awareness (PA) was applied in 70 children in the first grade of elementary school (35 students from public school and 35 from private school) at the beginning (pretest) and end (posttest) of the school year. Results: All children showed improvement in their performance when compared pre and posttest. In the pretest, the best scores were observed in the syllable level and in rhymes; however, comparing the pre with the posttests, the phonemic level showed the most significant improvement rates in the whole sample. The private school children had higher scores in most tests applied, as well as a higher total number of points compared to public school children in the pre and posttest. There was a decrease in the difference of the PA performance between schools at the end of the school year. Conclusion: All children showed improvement in PA skills with literacy process, although children from private schools had better performance, especially in the pretest, which can be a sign of the socioeconomic influence in the development of these skills. Syllabic and rhymes skills were developed before the literacy process and phonemic awareness skills were developed concurrently with this process. Also this study lays emphasis on the importance of the instruction in public schools in reducing the discrepancy between the abilities of these schools at the end of the school year, in this sample.
\end{abstract}

Keywords: Learning; Language; Child language; Language development; Education

Trabalho realizado no Departamento de Fonoaudiologia, Faculdade de Odontologia de Bauru, Universidade de São Paulo - USP - Bauru (SP), Brasil, com bolsa de Iniciação Científica concedida pelo Conselho Nacional de Pesquisa (CNPq).

(1) Programa de Pós-Graduação (Doutorado) em Estomatologia e Biologia Oral, Departamento de Ciências Odontológicas Aplicadas, Faculdade de Odontologia de Bauru, Universidade de São Paulo - USP - Bauru (SP), Brasil.

(2) Fonoaudióloga Clínica, Bauru (SP), Brasil.

(3) Programa de Pós-Graduação (Doutorado) em Fonoaudiologia, Faculdade de Odontologia de Bauru, Universidade de São Paulo - USP - Bauru (SP), Brasil. (4) Departamento de Fonoaudiologia, Faculdade de Odontologia de Bauru, Universidade de São Paulo - USP - Bauru (SP), Brasil.

Conflito de interesses: Não

Contribuição dos autores: TSG pesquisadora principal, elaboração de cronograma, revisão de literatura, coleta de dados e análise de dados, redação do artigo científico; TAPN pesquisadora principal, elaboração de cronograma, revisão de literatura, coleta de dados e análise de dados, $A P N$ revisão atualizada da literatura, análise de dados, redação e revisão do artigo; $P A P N$ coorientadora, elaboração da concepção da pesquisa junto à orientadora, revisão do artigo e aprovação da versão final; $S A L H$ orientadora, elaboração da concepção da pesquisa, organização da coleta e análise de dados, cronograma, análise de dados, elaboração e revisão do artigo, aprovação da versão final, submissão e trâmites do artigo.

Endereço para correspondência: Simone Aparecida Lopes-Herrera. Al. Octávio Pinheiro Brisola, 9-75, Vila Universitária, Bauru (SP), Brasil, CEP: 17012-90. E-mail: lopesimone@gmail.com

Recebido em: 28/6/2012; Aceito em: 24/7/2013 


\section{INTRODUÇÃO}

É durante os anos pré-escolares e início da escolarização que as crianças aprendem a ler e a escrever, desenvolvendo ainda a capacidade de prestar atenção à fala, analisando-a em diversos segmentos, que são os fonemas, as sílabas e as palavras ${ }^{(1)}$.

A consciência da natureza segmentada da fala, que deriva da capacidade de pensar e refletir conscientemente sobre a própria linguagem, denomina-se consciência fonológica (CF). É definida como sendo um conjunto de habilidades que vão desde a simples percepção global da extensão das palavras e de semelhanças fonológicas entre elas, até a segmentação e manipulação de sílabas e fonemas, desenvolvendo-se gradualmente, à medida que a criança vai tomando consciência do sistema sonoro da Língua ${ }^{(2)}$.

Estudos apresentados na literatura enfatizam a importância da CF no processo de alfabetização e na construção da linguagem escrita, bem como o emprego de atividades de consciência fonológica de forma preventiva ou reabilitadora ${ }^{(1-3)}$. Porém, há controvérsias $^{(4)}$ ao se discutir a influência dessa habilidade no processo de alfabetização em séries iniciais, questionando-se se há uma relação causal, uma relação de efeito, ou uma relação de causalidade recíproca. Alguns autores consideram a CF como preditora de bom desempenho na leitura, apresentando maior prevalência de déficits vinculados às condições socioeconômicas, devido ao estímulo e ao contato com material de leitura e escrita desde a fase pré-escolar ${ }^{(5,6)}$. Autores apontam que fatores socioculturais exercem influência negativa sobre o desenvolvimento da criança ${ }^{(7)}$.

O objetivo deste estudo foi verificar e comparar as habilidades de CF de crianças estudantes de escola pública e particular, em processo de alfabetização.

\section{MÉTODOS}

Este estudo teve aprovação do Comitê de Ética em Pesquisa da Faculdade de Odontologia de Bauru (FOB), da Universidade de São Paulo (USP), sob protocolo no 39/2006.

Participaram do estudo 70 crianças, alunas da primeira série do Ensino Fundamental, sendo 35 estudantes de escola pública e 35 estudantes de escola particular, na faixa etária entre 6 e 7 anos de idade. As escolas situavam-se em um mesmo bairro da cidade de Bauru (SP). Foram incluídas na amostra crianças sem problemas aparentes de visão, audição e/ou aprendizagem, conforme relato de suas professoras em entrevista à pesquisadora antes da coleta de dados. As crianças que apresentavam qualquer um desses problemas não foram incluídas na amostra. Houve prévia autorização da Secretaria Estadual de Educação (escola pública) e da Direção de ambas as escolas (pública e particular). Os pais e/ou responsáveis pelos participantes assinaram o Termo de Consentimento Livre e Esclarecido, autorizando a participação das crianças no estudo.

Os procedimentos descritos a seguir, foram aplicados em salas cedidas pelas diretorias das escolas (pública e particular). Os dados foram coletados no início do ano letivo (mês de fevereiro), quando as crianças ainda não haviam passado pelo processo de alfabetização (pré-teste), e no final do ano letivo (mês de novembro), quando já haviam passado por grande parte desse processo (pós-teste).

Para avaliação da consciência fonológica foi utilizado o Teste de Avaliação da Consciência Fonológica (TACF) ${ }^{(8)}$. Esse procedimento, de aplicação individual, contém seis subtestes: identificando rimas, contando sílabas, combinando fonemas iniciais, contando fonemas, comparando o tamanho das palavras e representando fonemas com letras. A pontuação máxima de cada tarefa é de cinco pontos, portanto há um escore máximo de 30 pontos. Em cada uma das escolas, nos dois momentos de avaliação (início e final do ano letivo), as crianças foram levadas a uma sala em que estavam dispostas mesas e cadeiras (carteiras escolares). Cada criança se acomodou em uma carteira, de forma a realizar o teste individualmente, recebendo um lápis, uma borracha e um caderno de testes elaborado por meio da compilação das folhas de testes. Foi apresentado um conjunto de páginas de demonstração para explicar aos alunos como deveria ser feito o TACF.

Os resultados foram submetidos à análise quantitativa, qualitativa e comparativa, verificando-se o nível de significância das diferenças encontradas. $\mathrm{Na}$ análise estatística comparativa, foram utilizados os testes de Mann-Whitney, na comparação do desempenho entre as escolas ao início e ao final do ano e o teste de Wilcoxon, na comparação do desempenho da amostra em cada prova, também ao início e ao final do ano. Para os dois testes estatísticos foi utilizado o nível de significância $\mathrm{p}<0,05$.

\section{RESULTADOS}

No total, a amostra foi composta por 70 crianças, sendo 37 meninos e 33 meninas (18 meninos e 17 meninas da escola pública; 19 meninos e 16 meninas da escola particular).

A média de acertos de cada prova, em porcentagem, e também do total máximo de pontos obtidos no pré-teste e no pós-teste, tanto nas crianças da escola pública quanto da particular, são demonstradas nas Tabelas 1 e 2, respectivamente.

Observou-se que houve expressiva melhora do desempenho ( $\mathrm{p}<0,05)$ entre pré e pós-teste nas provas 1 (identificando rimas), 2 (contando sílabas), 4 (contando fonemas), 5 (comparando o tamanho das palavras), 6 (representando fonemas com letras) e no total de pontos, para as crianças da escola pública; nas provas 2 (contando sílabas), 3 (combinando fonemas iniciais), 4 (contando fonemas), 5 (comparando o tamanho das palavras), 6 (representando fonemas com letras) e no total de pontos, para as crianças da escola particular.

A comparação dos valores obtidos, em porcentagem, pelas crianças da escola pública e da escola particular em cada uma 
Tabela 1. Desempenho das crianças das escolas pública e particular nas provas de consciência fonológica aplicadas ao início do ano letivo (pré-teste)

\begin{tabular}{lccc}
\hline Provas & Escola pública (\%) & Escola particular (\%) & Valor de $p$ \\
\hline Prova 1: Identificando rimas & 82 & 98 & 0,1255 \\
Prova 2: Contando sílabas & 78 & 79 & 0,8751 \\
Prova 3: Combinando fonemas iniciais & 73 & 95 & 0,2045 \\
Prova 4: Contando fonemas & 34 & 57 & $0,0447^{*}$ \\
Prova 5: Comparando o tamanho das palavras & 64 & 86 & 0,1901 \\
Prova 6: Representando fonemas com letras & 45 & 94 & $0,0016^{*}$ \\
Total das Provas & 74 & 85 & $0,0133^{*}$ \\
\hline
\end{tabular}

*Valores significativos $(p<0,05)-$ Teste de Mann-Whitney

Tabela 2. Desempenho das crianças das escolas pública e particular nas provas de consciência fonológica aplicadas ao final do ano letivo (pós-teste)

\begin{tabular}{lccc}
\hline Provas & Escola pública (\%) & Escola particular (\%) & Valor de $p$ \\
\hline Prova 1: Identificando rimas & 96 & 98 & 0,6569 \\
Prova 2: Contando sílabas & 93 & 96 & 0,1436 \\
Prova 3: Combinando fonemas iniciais & 93 & 99 & 0,1764 \\
Prova 4: Contando fonemas & 72 & 89 & $0,0001^{*}$ \\
Provas 5: Comparando o tamanho das palavras & 93 & 92 & 0,6470 \\
Prova 6: Representando fonemas com letras & 90 & 98 & 0,0544 \\
Total das Provas & 89 & 95 & $0,0000^{*}$ \\
\hline
\end{tabular}

*Valores significativos $(p<0,05)$ - Teste de Mann-Whitney

das provas de consciência fonológica aplicadas no pré-teste, e no pós-teste, e no total geral do teste é demonstrada na Tabela 3.

As crianças de escola pública apresentaram média de acerto de $89,4 \%$, enquanto que as de escola particular apresentaram média de $95,2 \%$. Na análise estatística, nota-se que foi significativa a diferença entre o desempenho das crianças da escola pública e particular no desempenho geral do teste.

Comparando-se o pré-teste com o pós-teste, observamos que todas as crianças da amostra obtiveram melhora de desempenho em todas as provas, embora essa melhora tenha sido mais acentuada nas crianças da escola particular.

No escore total do teste, as crianças de escola particular apresentaram resultados melhores que os das crianças de escola pública ( $89 \%$ e $95 \%$, no pré e pós-teste, respectivamente, contra $74 \%$ e $89 \%$ ), mas observou-se que a diferença entre os resultados foram bem menores no pós-teste do que no pré-teste. Contudo, em ambas as situações, todas as crianças da amostra obtiveram melhora significativa no escore total do teste (Figura 1).

\section{DISCUSSÃO}

No presente estudo, observou-se que o desempenho das habilidades de consciência fonológica foi significativamente aperfeiçoado com o processo de alfabetização, em todas as crianças da amostra. Essa análise pôde ser feita comparando-se o desempenho de todas as crianças em cada prova no pré e no pós-teste, em ambas as escolas, em que houve diferença na maioria das provas, com exceção da prova 1 (Identificando rimas), na escola particular, na qual as crianças já haviam apresentado um alto índice de acerto no pré-teste, e da prova 3 (combinando fonemas iniciais) da escola pública. De acordo

Tabela 3. Comparação dos valores obtidos pelas crianças das escolas pública e particular nas provas de consciência fonológica aplicadas

\begin{tabular}{|c|c|c|c|c|c|c|}
\hline \multirow{2}{*}{ Provas } & \multicolumn{3}{|c|}{ Escola pública } & \multicolumn{3}{|c|}{ Escola particular } \\
\hline & Pré-teste (\%) & Pós-teste (\%) & Valor de $p$ & Pré-teste (\%) & Pós-teste (\%) & Valor de $p$ \\
\hline Prova 1 & 82 & 96 & $0,0184^{*}$ & 98 & 98 & 0,1643 \\
\hline Prova 2 & 78 & 93 & $0,0024^{*}$ & 79 & 96 & $0,0000^{*}$ \\
\hline Prova 3 & 73 & 93 & 0,1082 & 95 & 99 & $0,0203^{*}$ \\
\hline Prova 4 & 34 & 72 & $0,0001^{*}$ & 57 & 89 & $0,0000^{*}$ \\
\hline Prova 5 & 64 & 93 & $0,0007^{*}$ & 86 & 92 & $0,0009^{*}$ \\
\hline Prova 6 & 45 & 90 & $0,0000^{*}$ & 94 & 98 & $0,0000^{*}$ \\
\hline Total & 74 & 89 & $0,0000^{*}$ & 85 & 95 & $0,0000^{*}$ \\
\hline
\end{tabular}

*Valores significativos $(p<0,05)$ - Teste de Wilcoxon 


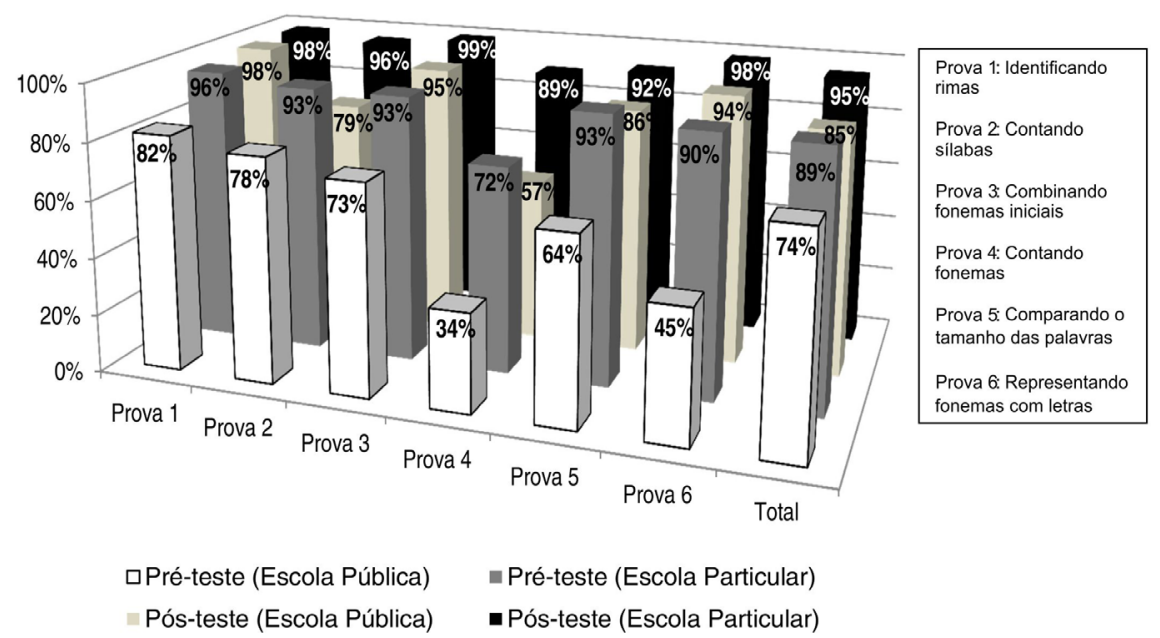

Figura 1. Comparação dos valores obtidos pelas crianças das escola pública e particular nas provas de consciência fonológica aplicadas no pré e do pós-teste

com a literatura, o desempenho das habilidades de CF aprimora-se conforme a escolaridade aumenta ${ }^{(9)}$.

As habilidades básicas de CF desenvolvem-se antes do processo de alfabetização e outras, mais complexas, desenvolvem-se concomitantemente a esse processo ${ }^{(9)}$. Em relação a essa informação, os resultados deste estudo mostraram que os melhores desempenhos alcançados no pré-teste, por todas as crianças da amostra, ocorreram nas provas que envolviam rimas e habilidades silábicas. Esse dado confirma os resultados de outra pesquisa ${ }^{(10)}$, que apontou que algumas habilidades são mais precoces que outras, sendo que a sensibilidade para rimas já está presente em crianças muito pequenas (de 3 anos) e a habilidade de segmentar as palavras em sílabas é observável em crianças a partir de 4 anos. Confirmando essa informação, outros autores ${ }^{(11)}$ demonstraram que, durante as três séries iniciais do ensino fundamental, não houve diferença significativa nas habilidades de consciência de rimas e silábica, porém houve diferença na consciência fonêmica.

Desta forma, os resultados deste estudo que apontam melhor desempenho de todas as crianças nas habilidades de rimas e contagem de sílaba e pior desempenho nas atividades de consciência fonêmica, concordaram com a literatura ${ }^{(12,13)}$, que afirma que as tarefas fonêmicas são adquiridas posteriormente às silábicas. A segmentação fonêmica requer a descoberta de unidades mínimas não distintas na cadeia contínua de fala e, mesmo nesse nível de segmentação, algumas tarefas são mais difíceis que as outras, dependendo da estrutura segmentar apresentada ${ }^{(14)}$.

O fato das crianças desta amostra terem desenvolvido as habilidades de consciência fonológica com a alfabetização, principalmente as que envolviam consciência fonêmica, como descrito, pode relacionar-se com o evento de que, ao mesmo tempo em que a consciência fonêmica só se desenvolve com a alfabetização, o processo de aquisição de leitura e escrita depende dessa consciência do fonema para atribuir-lhe um signo, o grafema. No entanto, a consciência fonêmica e o conhecimento das correspondências grafema-fonema andam em paralelo para que se tenha domínio dos princípios do sistema alfabético ${ }^{(15)}$, o que também foi observado no presente estudo, ou seja, com o aperfeiçoamento das habilidades de consciência fonêmica, houve melhora na relação fonema-grafema (prova 6), na comparação do pré-teste com o pós-teste.

Estudos relatam que as crianças que passaram por um treinamento de consciência fonológica conseguiram melhor pontuação em testes de consciência fonológica e evoluíram no estágio de desenvolvimento da escrita ${ }^{(3,16)}$. As crianças que já passaram pelo processo de alfabetização e que estão nos níveis silábico-alfabético e alfabético, têm melhor desempenho nas provas de consciência fonológica que as crianças que ainda não foram alfabetizadas ${ }^{(17)}$, ou seja, que estão nos níveis pré-silábico e silábico, o que também concorda com o presente estudo.

Portanto, no presente estudo, pode-se afirmar que há uma correlação positiva entre o desenvolvimento da consciência fonêmica e melhora nas habilidades de escrita das mesmas, pois quando as crianças passaram a ter maior habilidade em realizar a combinação dos fonemas iniciais das palavras e na contagem dos fonemas, foi observada, também, melhora na representação dos fonemas pelos grafemas, ou seja, a habilidade de escrita das palavras foi aperfeiçoada. Sendo assim, a consciência fonológica é um importante componente para os leitores iniciantes ${ }^{(1,17,18)}$.

A partir deste momento da discussão, serão abordadas as diferenças no desempenho da $\mathrm{CF}$ entre as escolas pública e particular. Um dado importante deste estudo foi a observação de que as crianças da escola particular já apresentavam conhecimento em nível fonêmico no pré-teste, pois obtiveram bom desempenho na combinação de fonemas iniciais (prova 4) e representação de fonemas por letras (prova 6), habilidade pouco desenvolvida nas crianças da escola pública, sendo essas as únicas habilidades que diferiram estatisticamente entre as escolas, embora as crianças de escola particular tenham apresentado melhor desempenho em todas as provas do pré-teste. 
No entanto, observou-se que, no pós-teste, as provas que envolviam nível fonêmico foram as que obtiveram maior índice de melhora, principalmente na escola pública.

Com base nesses achados, pode-se dizer que a maioria das crianças da escola particular já estava alfabetizada no pré-teste, pois na prova 6 (representando fonemas com letras), houve alta média de acerto, o que não ocorreu na escola pública. Um estudo semelhante também demonstrou que crianças alfabetizadas demonstram maior habilidade fonológica e que fatores externos, como nível socioeconômico, nível cultural, pouca estimulação no processo de ensino, aprendizagem e distorção e série/idade parecem contribuir para um baixo desempenho das habilidades de consciência fonológica ${ }^{(19)}$.

Dessa forma, o fato das crianças da escola particular já possuírem melhor desempenho em consciência fonológica que as crianças da escola pública no início da primeira série, principalmente em relação à consciência fonêmica, permite duas considerações: a primeira, é a influência de fatores socioeconômicos nas habilidades básicas de consciência fonológica e a segunda é a possibilidade de, na pré-escola, as crianças de escola particular terem recebido maior estimulação para o desenvolvimento dessas habilidades, não apenas na escola, mas também no ambiente familiar. Assim, este é um campo que pode ser explorado em pesquisas futuras.

A literatura relata fatores que parecem influenciar o aprendizado escolar geral, como renda familiar, depressão materna, número de pessoas da família ${ }^{(20)}$, oferta de recursos (brinquedos e jogos adequados), exposição à leitura no ambiente domésti$\mathrm{co}^{(21)}$, escolaridade e idade dos pais ${ }^{(22)}$.

Seguindo esse raciocínio, dentre os aspectos familiares, a exposição à leitura no ambiente doméstico mostra-se bastante relevante para o desempenho escolar da criança ${ }^{(21)}$, contribuindo especificamente para o reconhecimento de palavras ${ }^{(23)}$ e para o desenvolvimento da consciência fonológica, um dos melhores preditores da leitura proficiente ${ }^{(24)}$.

Assim, se a experiência de leitura dos pais não é boa, com história pessoal de dificuldade escolar, vinculada a um baixo nível de escolaridade, poderá ser mais difícil que esses pais atuem como mediadores e estimuladores do processo de aprendizagem de leitura e escrita de seus filhos ${ }^{(7)}$, o que possivelmente esteja relacionado com a diferença encontrada no pré-teste, nas habilidades de consciência fonológica, entre as escolas pública e particular.

Outro achado relevante neste estudo foi que, no pós-teste, a diferença no desempenho entre as escolas particular e pública ocorreu somente na prova 4 (contando fonemas), com melhor desempenho na escola particular. Como já descrito anteriormente, no pré-teste, houve diferença entre as escolas na prova 4 e na prova 6 (representando fonemas com letras). Considerando que os resultados deste estudo demonstraram que o ensino da escola pública minimizou a diferença inicial no desempenho da CF entre as escolas, entendemos que, especialmente nas escolas públicas brasileiras, o professor precisa estar preparado para lidar com a diversidade de ambientes socioculturais e de conhecimentos de base das crianças ${ }^{(25)}$. Portanto, pode-se dizer que os aspectos escolares, como a qualidade dos professores e/ ou métodos de ensino, têm impacto nas habilidades de leitura e escrita de crianças de séries iniciais de escolarização ${ }^{(26)}$.

Uma pesquisa ${ }^{(27)}$ demonstrou que os ganhos produzidos pelo treino de consciência fonológica e de correspondência grafo-fonêmica de crianças de baixo nível socioeconômico foram maiores do que os ganhos de crianças de médio nível socioeconômico. Os autores explicam esse achado com o fato de que as crianças com maior nível socioeconômico dispõem de outros recursos para sanar suas dificuldades, como a própria família ou professores de reforço, e as crianças de baixo nível socioeconômico não dispõem de uma estrutura familiar que incentive a leitura e a escrita. Ou seja, não possuem uma fonte de informação alternativa (no caso, a família) que supra as falhas educacionais e que forneça instruções básicas de correspondências entre as letras e os sons. De acordo com os autores, o estudo citado oferece às escolas um procedimento de intervenção que constitui um recurso econômico e eficaz em auxílio à alfabetização de seus alunos.

Outra pesquisa semelhante ${ }^{(28)}$ demonstrou que, alguns meses após o encerramento de um programa de treinamento de $\mathrm{CF}$ em pré-escolares de escolas pública e particular, no ano letivo seguinte ( $1^{\mathrm{a}}$ série), entre os grupos experimental e controle da escola particular, a diferença significativa de desempenho em consciência fonológica e em termos de leitura desaparecia, levando a crer que isso tenha se devido ao potencial enriquecedor do ambiente familiar das crianças da escola particular, durante as férias. Já nos alunos da escola pública, após esse período de férias, observou-se que a diferença significativa entre os grupos experimental e controle no desempenho em consciência fonológica e na prova de leitura se manteve. Os resultados demonstraram a importância do treinamento com consciência fonológica para alunos de escolas públicas (que não dispõem desse amparo da família por motivos educacionais e sociais), como um pré-requisito fundamental para a compreensão do princípio alfabético.

Os resultados encontrados no presente trabalho, nas situações pré e pós-teste, demonstraram que, na amostra analisada, as crianças de escola particular obtiveram melhor desempenho em todas as provas e no número total de pontos nas duas situações. Esses resultados foram semelhantes aos encontrados em outro estudo, em que as crianças de escola particular obtiveram melhor desempenho nos subtestes de manipulação silábica, transposição silábica e no total de pontos obtidos no teste de consciência fonológica ${ }^{(29)}$.

Embora haja extensa literatura sobre o desenvolvimento das habilidades de CF, os fatores socioeconômicos e culturais que influenciam o desenvolvimento dessas habilidades e que também se relacionam com as dificuldades de leitura e escrita, encontram-se pouco definidos e explorados no meio científico, o que deveria ser foco de estudos futuros. Sabe-se que o 
ambiente é importante, porque fornece estímulos e possibilita experiências fundamentais para o desenvolvimento da linguagem, incluindo a linguagem escrita, como meio principal de interação social ${ }^{(23,24)}$.

Contudo, as estratégias baseadas em evidências no desenvolvimento da consciência fonológica e suas inter-relações com fatores socioeconômicos precisam ser divulgadas para os profissionais da educação ${ }^{(11)}$, sendo relevante o treinamento de tais habilidades o mais cedo possível, quando alguma dificuldade é detectada, pois as crianças com dificuldades de consciência fonológica (por exemplo, na habilidade de rima) aparentam ser um grupo de risco para ocorrência de problemas no desenvolvimento da leitura ${ }^{(30)}$.

\section{CONCLUSÃO}

Todas as crianças da amostra apresentaram melhora nas habilidades de consciência fonológica com o processo de alfabetização. As habilidades de rimas e as habilidades silábicas desenvolveram-se antes do processo de alfabetização e as habilidades de consciência fonêmica foram desenvolvidas concomitantemente com esse processo, o que aponta a estrita ligação entre as habilidades de consciência fonológica e os estágios de desenvolvimento da leitura e da escrita.

As crianças de escola particular demonstraram melhores habilidades de consciência fonológica no início da alfabetização, principalmente em relação à consciência fonêmica, sendo este um indício da influência dos aspectos socioeconômicos no desenvolvimento das habilidades de consciência fonológica. A redução da discrepância dessas habilidades entre as escolas ao final do ano letivo deveu-se ao ensino da escola pública. Dessa forma, sugere-se que os aspectos socioeconômicos e culturais no desenvolvimento da consciência fonológica sejam alvo de estudos futuros e melhor investigados.

\section{REFERÊNCIAS}

1. Dambrowski AB, Martins CL, Theodoro JL, Gomes E. Influência da consciência fonológica na escrita de pré-escolares. Rev CEFAC. 2008;10(2):175-81.

2. Nunes C, Frota S, Mousinho R. Consciência fonológica e o processo de aprendizagem da leitura e da escrita: implicações teóricos para o embasamento da prática fonoaudiológica. Rev CEFAC. 2009;11(2): 207-212

3. Frohlich LP, Metz D, Petermann F. Program for the enhancement of phonological awareness in preschoolers. Kindheit und Entwicklung. 2009; 18(4):204-212.

4. Basso FPA. A estimulação da consciência fonológica e sua repercussão no processo de aprendizagem da lecto-escrita [dissertação]. Santa Maria: Universidade Federal de Santa Maria; 2006.

5. Billard C, Bricout L, Ducot B, Richard G, Ziegler J, Fluss J. Reading, spelling and comprehension level in low socioeconomic backgrounds: Outcome and predictive factors. Revue d'Épidémiologie et de Santé Publique. 2010Apr; 58(2):101-10.

6. Townsend M, Konold TR. Measuring early literacy skills: a latent variable investigation of the phonological awareness literacy screening for preschool. J Psychoeduc Assess. 2010Apr;28(2):11528.

7. Enricone JRB, Salles JF. Relação entre variáveis psicossociais familiares e desempenho em leitura/escrita em crianças. Psicologia Escolar e Educacional. 2011;15(2):199-210.

8. Adams MJ, Foorman BR, Lundberg I, Beeler T. Consciência fonológica em crianças pequenas. Porto Alegre: Artmed; 2006.

9. Alcock KJ, Ngorosho D, Deus C, Jukes MC. We don't have language at our house: disentangling the relationship between phonological awareness, schooling, and literacy. Br J Educ Psychol. 2010Mar;80(1):55-76.

10. Stanovich KE, Cunningham AE, Cramer BE. Assessing phonological awareness in kindergarter children: issues of task comparability. J Exp Child Psychol. 1984;38(2):175-90.

11. Berninger VW, Abbott RD, Nagy W, Carlisle J. Growth in phonological, orthographic, and morphological awareness in grades 1 to 6. J Psycholinguist Res. 2010Apr;39(2):141-63.

12. Thatcher KL. The development of phonological awareness with specific language-impaired and typical children. Psychology in the Schools. 2010May;47(5):467-80.

13. Vloedgraven D, Verhoeven L. The nature of phonological awareness throughout the elementary grades: An item response theory perspective. Learn Individ Differ. 2009Jun;19(2):161-69.

14. Godoy DMA. Testes de consciência fonológica e suas relações com a aprendizagem da leitura no português [dissertação]. Florianópolis: Universidade Federal de Santa Catarina; 2001.

15. Godoy DMA. O papel da consciência fonológica no processo de alfabetização. Pro Fono. 2003Set-Dez;15(3):241-49.

16. Fadine CC, Capellini AP. Treinamento de habilidades fonológicas em escolares de risco para a dislexia. Psicopedagogia. 2011;28(85):3-13.

17. Tenório SMPCP, Ávila CRB. Processamento fonológico e desempenho escolar nas séries iniciais do ensino fundamental. Rev CEFAC. 2012;14(1):30-8

18. Furlan SA, Fukuda MTH, Granzotti RBG. Habilidades de consciência fonológica em criança portadora de síndrome da imunodeficiência adquirida: pré e pós-terapia fonoaudiológica. J Soc Bras Fonoaudiol. 2012;24(1):86-90.

19. Paes CTS, Pessoa ACRG. Habilidades fonológicas em crianças não alfabetizadas e alfabetizadas. Rev CEFAC. 2005 AbrJun;7(2):149-57.

20. Piccolo LR, Falcetol OG, Fernandes CL, Levandowski DC, GrassiOliveira R, Salles JF. Variáveis psicossociais e desempenho em leitura de crianças de baixo nível socioeconômico. Psic Teor e Pesq. 2012;4(28):389-98.

21. Duursma E, Pan BA, Raikes H. Predictors and outcomes of lowincome fathers'reading with their toddlers. Early Child Res Q. 2008;23(3):351-65.

22. Skibbe LE, Justice LM, Zucker TA, McGinty AS. Relations among maternal literacy beliefs, home literacy practices, and the early 
literacy skills of preschoolers with specific language impairment. Early Education and Development. 2008;19(1):68-88.

23. Peeters M, Verhoeven L, de Moor J, van Balkom H, van Leeuwe J. Home literacy predictors of early reading development in children with cerebral palsy. Res Dev Disabil. 2009May-Jun;30(3):445-61.

24. Kim YS. The relationship between home literacy practices and developmental trajectories of emergent literacy and conventional literacy skills for Korean children. Reading and Writing. 2009;22(1):57-84.

25. Carvalho AMP. Baixo rendimento escolar: uma visão a partir do professor. In: Funayama CAR (Org.). Problemas de aprendizagem: enfoque multidisciplinar. Campinas: Alínea; 2000. p. 115-46.

26. Leybaert J, Alégria J, Deltour JJ, Skinkel R. Aprender a ler: o papel da linguagem, da consciência fonológica e da escola. In: Grégoire J, Piérart B (Orgs.). Avaliação dos problemas de leitura: os novos modelos teóricos e suas implicações diagnósticas. Porto Alegre: Artes Médicas; 1997. p. 143-66.
27. Capovilla AGS, Capovilla FC. Efeitos do treino de consciência fonológica em crianças com baixo nível sócio-econômico. Psicol Reflex Crit. 2000Jan-Jun;13(1):7-24.

28. Santos AA. A influência da consciência fonológica na aquisição da leitura e da escrita. In: Sisto FF, Campos GC, Fini LDT, Souza MTCC, Brenelli RP (Orgs). Atuação psicopedagógica e aprendizagem escolar. Petrópolis: Vozes; 1996. p. 213-47.

29. Pedras CTPA, Geraldo T, Crenitte PAP. Consciência fonológica em crianças de escola pública e particular. Rev Soc Bras Fonoaudiol. 2006;11(2):65-9.

30. Krajewski K, Schneider W. Exploring the impact of phonological awareness, visual-spatial working memory, and preschool quantitynumber competencies on mathematics achievement in elementary school: findings from a 3-year longitudinal study. J Exp Child Psychol. 2009Ago;103(4):516-31. 